\title{
POSITIEWE PRESTASIEBEOORDELING
}

\author{
S.W. KRüGEL \\ DEPARTEMENT BEDRYF- EN PERSONEELSIELKUNDE \\ POTCHEFSTROOMSE UNIVERSITEIT VIR CHO
}

\begin{abstract}
In this article a plea is being made for a more positive approach to performance appraisal. The subject is discussed under the following headings: Shortcomings in the traditional performance appraisal methods; Guidelines for better performance rating; and The design of an effective performance appraisal procedure. The conclusion is reached that the solution to performance rating problems lies in the direction of a pursuance of a "systems" or comprehensive approach to rating problems; with special reference to human factors, structural aspects, dynamic aspects, and environmental factors.
\end{abstract}

In alle organisasies, klein sowel as groot word die prestasie van werkers beoordeel. Dit is 'n onvermydelike proses, die produk waarvan gebruik word vir onder andere salarisverhogings, bevorderings en personeelontwikkeling. Al verskil tussen organisasies wat prestasiebeoordeling betref is die metode of benadering wat gevolg word. Benaderings tot prestasiebeoordeling kan gerieflikheidshalwe in twee breë kategorieë onderverdeel word; te wete die tradisionele benadering en die stelsels- of komprehensiewe benadering.

\section{DIE TRADISIONELE PRESTASIEBEOORDELINGSTELSELS}

Flippo (1976, p. 265) onderskei tussen die volgende sewe metodes: Die Rangordemetode, Persoon-tot-persoon vergelyking, Graderingsmetode, Grafiese skale, Kontrolelyste, Geforseerde-keuse-beskrywings en Kritiese insidente.

Ondervinding het bewys dat die tradisionele benadering in die reël op 'n negatiewe wyse deur die meeste werkers en bestuurders (dit wil sê die beoordelaars) bejeën word. Likert (1959, p. 75) stel dit soos volg: "The fundamental flaw in current review procedures is that they compel the superior to behave in a threatening, rejecting and ego-deflating manner with a sizable proportion of his staff. This pattern of relationship between the superior and 
subordinate not only affects the subordinate but also seriously impairs the capacity of the superior to function effectively".

Vir die doel van hierdie artikel word die hoofdoel van prestasie- of merietebeoordeling beskou as die akkurate meting van die ekonomiese waarde van die werker vir die onderneming waarvoor hy werk.

Daar is veral vier hoof probleemareas wat die doeltreffendheid van tradisionele prestasiebeoordelingsprogramme in die nastrewing van hierdie doelwit verminder en skeptisisme by beide werknemers, toesighouers en bestuurders tot gevolg het. Hulle is:

- menslike vooroordele,

- beoordelingsvorms en -praktyke wat nie daarin slaag om menslike vooroordele uit te skakel of te verminder nie,

- $\quad$ gebrekkige kommunikasie, en

- ongunstige beoordelingsklimaat.

Die eersgenoemde probleem, naamlik die menslike vooroordele van toesighouers en bestuurders is sekerlik die mees onvoorspelbare en onoorkomelike van die vier genoemde struikelblokke. Trouens die beste pogings ten spyt, is dit te betwyfel of vooroordele ooit totaal uitgeskakel sal kan word. Selfs die beste toesighouers en bestuurders, bly mense en is as sodanig geneig om elkeen sy eie standaarde aan te lê om die prestasie van sy ondergeskiktes te meet. So word elke beoordelaar se objektiwiteit in 'n sekere mate nadelig beïnvloed deur vooroordele ten opsigte van onder andere geslag, ras, ouderdom, kleredrag, voorkoms, opvoedingspeil, godsdiens en persoonlike vriendskappe.

Waar 'n prestasiebeoordelingstelsel op persoonlike eienskappe gebaseer is, kan vooroordele by die beoordelaar ' $n$ verskuiwing in die prestasiebeoordelingsprofiel laat plaasvind. Dit kan byvoorbeeld gebeur as gevolg van die feit dat onlangse gebeurtenisse, maandelange konstante goeie of swak prestasie, oorskadu. Ook kan dit gebeur dat 'n uitstaande persoonlike eienskap meer gewig gegee word as al die ander eienskappe (die sogenaamde stralekranseffek). Ander moontlike redes vir 'n verskuiwing in 'n akkurate prestasiebeoordelingsprofiel kan een of meer van die volgende behels: eerstens, dat een werknemer se goeie eienskappe as maatstaf gebruik word om ander werkers se prestasie teen te meet; tweedens, dat moeilike werk op dieselfde basis beoordeel word as maklike werk of dat nie-vergelykbare poste met mekaar vergelyk word; derdens dat beoordelaars slegs die 
goeie eienskappe van persone van wie hulle hou, raaksien, of omgekeerd, slegs die swak eienskappe raaksien van diegene van wie hulle nie hou nie. Samevattend in die woorde van (Sikula, 1976, p. 211):

"Certain general types of rating problems are common to many, if not all, of these methods. These common problems include:

(1) the halo-effect; (2) lenienc or strictness; (3) central tendency; (4) personal bias; and (5) appraisal purposes".

'n Tweede struikelblok wat die effektiwiteit van prestasiebeoordeling kan ondermyn is, soos hierbo genoem, swak beoordelingspraktyke wat te kort skiet by die uitskakeling van beoordelaarsvooroordele. In hierdie verband kan die volgende vier praktyke en prosedures uitgesonder word as van die belangrikste sondebokke: eerstens, oppervlakkige prestasiestandaarde, dit wil sê waar prestasiebeoordelings gegrond word op subjektiewe en abstrakte begrippe soos betroubaarheid, lojaliteit, houding, belangstelling, ambisie, potensiaal, inisiatief, oordeelsvermoë, en so meer. Die probleem by die gebruik van hierdie eienskappe as prestasiemaatstawwe is geleë in die feit dat dit moeilik meetbaar is en dus te kort skiet as objektiewe maatstaf om die ekonomiese waarde van 'n werknemer akkuraat te meet. Met persoonlikheidseienskappe as standaard val die klem verkeerdelik op die beoordeling van die persoon en nie op sy werklike prestasie in die werksituasie nie. Byvoorbeeld, 'n werker kan 'n uur vroeër by die werk opdaag en 'n halfuur na normale sluitingstyd vertrek, en tog baie min verrig. Hy mag verder baie ambisieus wees wat in werklikheid niks beteken indien hy nie in staat is om aan die vereistes van sy pos te voldoen nie. Op dieselfde wyse is al die voortreflike persoonlikheidseienskappe hierbo genoem, op sigself van geen waarde indien dit nie gepaard gaan met voortreflike werkverrigting nie.

Strauss and Sayles (1972, p. 513) stel dit so: "The ratings secured are of little use in helping an employee do a better job. For instance, it is hard for a man to make a real change in his 'personality', though he might put up a false front and pretend to be, in the words of one typical form, 'radiant, confident, cheerful, courteous".

Die tweede probleem, naamlik prestasiemeting wat nie aan werklike prestasie gekoppel is nie, word hoofsaaklik veroorsaak deur beoordelaars (hetsy toesighouers of bestuurders) wat in gebreke bly om volledige produksierekords in stand te hou. Die gevolg is dat daar op die geheue staatgemaak moet word wanneer beoordelings gedoen word. 
Die derde probleem in verband met prestasiebeoordelingsvooroordele kan herlei word na die tydstip waarop beoordelings gedoen word. Wanneer daar van beoordelaars verwag word om 'n groot getal prestasiebeoordelings binne 'n kort periode af te handel ('n prosedure wat dikwels in die praktyk voorkom) word 'n groot mate van akkuraatheid ingeboet veral in gevalle waar volledige produksierekords nie bestaan nie en die beoordelaars op hul geheue moet staatmaak.

'n Vierde probleem ontstaan in gevalle waar loon- en salarisskale direk gekoppel word aan prestasiepuntetellings. Wanneer dit gebeur bestaan die gevaar van opwaartse of afwaartse manipulasie van puntetellings (of persentasies) om by die salarisbegroting aan te pas: met die gevolglike gevaar dat 'n prestasiebeoordelingsprogram 'n middel kan word om salaris- en loontoekennings te rasionaliseer.

Daar is genoem dat gebrekkige kommunikasie 'n derde faktor is wat 'n tegnies volmaakte prestasiebeoordelingstelsel skipbreuk kan laat ly. Kommunikasie kortsluitings kan in beide rigtings ontstaan, enersyds in 'n afwaartse rigting tussen hoof en ondergeskikte en andersyds, in 'n opwaartse rigting tussen ondergeskikte en hoof .

Daar bestaan verskeie redes waarom kommunikasieprobleme kan ontstaan en verhoudinge tussen hoof en ondergeskikte kan vertroebel. Prestasiebeoordelingsonderhoude wat gebaseer is op onakkurate en bevooroordeelde prestasieverslae is sekerlik een van die vernaamste oorsake waarom sommige prestasiebeoordelingstelsels misluk. Dit wek nie alleen misnoeë en antipatie by die individuele werker nie maar kring in die reël uit tot 'n algemene agterdogtigheid by ander werkers oor die regverdigheid van die betrokke stelsel.

'n Ander versperring in die pad van goeie kommunikasie is die negatiewe houding van sommige beoordelaars met betrekking tot die prestasiebeoordelingsonderhoud. In hierdie verband kan genoem word die gebrek aan moed by beoordelaars om reguit te praat, pogings om redenasies te omseil, subtiele vyandiggesindheid en 'n outoritêre houding. Sommige toesighouers gaan selfs sover om prestasie-onderhoude as 'n tipe dissiplinêre maatreël te gebruik of om alle werknemers 'n goeie of gemiddelde meriete-aanslag te gee, bloot om ontevredenheid en argumente te vermy (die sogenaamde sentrale tendens).

Ten slotte kan prestasiebeoordelingstelsels skipbreuk ly as gevolg van 'n swak prestasiebeoordelingsomgewing. Met "swak omgewing" word onder andere bedoel ondoeltreffende salarisadministrasie en -bevorderingspraktyke. Die volgende dien as voorbeelde van probleemareas in hierdie sektor: 'n té groot gewig aan senioriteit, administratiewe 
onbuigsaamheid, buitensporige verhoging van byvoordele as persentasie van totale vergoeding, terughouding van verhogings aan verdienstelike werknemers, en nepotisme - om slegs 'n paar te noem.

\section{ENKELE RIGLYNE VIR 'N BETER (DIT WIL SÊ MEER POSITIEWE) MERIETE-AANSLAG}

Gesien teen die agtergrond van die voorafgaande bespreking is dit heel duidelik dat die tradisionele metodes van prestasiebeoordeling ernstige leemtes en tekortkominge openbaar; in so 'n mate dat konvensionele merietebeoordelingstelsels dikwels bestempel word as die mees gebruikte en misbruikte bestuursinstrumente. In die woorde van Douglas McGregor (1957, p. 90): "The conventional approach, unless handled with consummate skill and delicacy, constitutes something dangerously close to a violation of the integrity of the personality. Managers are uncomfortable when they are placed in the position of 'playing God'. The respect we hold for the inherent value of the individual leaves us distressed when we must take responsibility for judging the personal worth of a fellow man. Yet the conventional approach to appraisal forces us, not only to make such judgements and to see them acted upon, but also to communicate them to those we have judged. No wonder we resist!"

Die klaarblyklike oplossing van bovermelde beoordelingsprobleme is geleë in die nastrewing van 'n meer konsekwente en positiewe prestasiebeoordelingstelsel, dit wil sê 'n objektiewe stelsel wat prestasie- eerder as persoons-georiënteerd is. Een moontlike oplossing tot die probleem is te vinde in die toepassing van 'n stelsels- of komprehensiewe benadering tot prestasiebeoordeling, met ander woorde ' $n$ benadering wat die hele organisatoriese opset in aanmerking neem. Vier faktore is hier van belang, te wete, (i) die menslike aspekte; (ii) die strukturele aspekte van die program, met besondere verwysing na beoordelingsvorms en beoordelingspraktyke; (iii) die dinamiese aspekte van die program, waaronder kommunikasie en terugvoering van besondere belang is, en (iv) die omgewing waarbinne die program fungeer.

Die volgende riglyne, indien konsekwent toegepas, behoort 'n daadwerklike bydrae te lewer tot die daarstelling van 'n meer akkurate en positiewe prestasiebeoordelingstelsel. In die eerste plek behoort daar gepoog te word om die gehalte van bestuur en toesighouding te verbeter. Dit kan gedoen word deur versigtige keuring sodat slegs bevoegde en prestasiegeoriënteerde persone in leiersposisies aangestel word. Opleiding van beoordelaars in die 
tegnieke van rekordhouding, personeelhantering en veral onderhoudvoering is 'n essensiële vereiste vir sukses. Geen beoordelingstelsel hoe perfek dit ook al mag wees, kan suksesvol geïmplementeer word deur onbekwame en swak ingeligte leiers en beoordelaars nie (Haynes, 1978, pp. 104-107). Dieselfde beginsel geld natuurlik ook wat die keuring, opleiding en motivering van werknemers betref. Daar moet naamlik toegesien word dat slegs prestasiegeoriënteerde werkers in diens geneem word, dat hulle deeglik en sistematies opgelei, en billik vergoed word.

In die tweede plek, behoort daar van prestasiegeoriënteerde meriete-aanslagvorms gebruik gemaak te word, dit wil sê vorms wat daarop gerig is om die resultate in die werk te beklemtoon en die ekonomiese waarde van die werker te meet.

Die prestasiestandaarde wat gebruik word moet op die kerntake in posbeskrywings gebaseer wees, en nooit, soos voorheen vermeld, persoonlikheidseienskappe insluit nie. 'n Syferlose beskrywende skaal om prestasie op die aanslagvorm aan te dui, word in die reël verkies bo 'n syferskaal. Woorde soos uitstaande, baie goed, goed, onaanvaarbaar, ensovoorts is minder emosioneel belaai en vir die werker meer aanvaarbaar as 'n $60 \%, 50 \%$ of $40 \%$ aanslag.

Toesighouers en bestuurders behoort ' $n$ volledige stel gegewens van al die prestasies van die werker op te bou ten einde 'n objektiewe meriete-aanslag te maak. Dit is verder wenslik dat elke werker aktief betrek word in die opstel en formulering van doelwitte wat hom raak. So 'n prosedure sal die werker in staat stel om homself te beoordeel, en sodoende baie van die besware en bedenkinge teen 'n eensydige meriete-aanslag uitskakel. "The defining characteristic of the management by objectives (MBO) approach to appraisal is that the superior and subordinate agree on specific performance objectives, and on how achievement of these objectives is to be measured, and that subordinates are then evaluated in terms of these highly personalized agreed-upon measures and objectives" (Orpen, 1979, p. $151)$.

Dit is verder van belang dat beoordelaars alle meriete-aanslae rondom mense skeduleer, dit wil sê dat die prestasiebeoordelingstelsel by die mens aangepas word en nie andersom nie. Beoordeling van die prestasie van individuele werkers behoort dus op 'n soepel wyse toegepas te word, byvoorbeeld maandeliks, kwartaalliks, halfjaarliks of by die afhandeling van 'n bepaalde projek of program; afhangende van die besondere omstandighede. Nuwe aanstellings verdien spesiale aandag en behoort in die reël meer dikwels aangeslaan te word as werkers wat reeds gevestig en jare diens agter die rug het. 
'n Derde riglyn om prestasiebeoordeling te verbeter is om tydens die prestasiebeoordelingsonderhoud deurgaans 'n positiewe benadering te volg deur die klem te laat val op maniere hoe om die werker se groei en ontwikkeling te stimuleer en sy produktiwiteit te verhoog (Beer en Ruh, 1976, pp. 56-66).

Prestasiebeoordelingsonderhoude is nie maklik om te voer nie. Indien swak gehanteer, kan dit meer kwaad as goed doen en aanleiding gee tot antipatie, agterdog, vyandiggesindheid en selfs openlike verset.

Die gesindheid van die onderhoudvoerder teenoor die onderhoud en die werknemer is sekerlik een van die belangrikste faktore wat die sukses of mislukking van 'n prestasiebeoordelingsonderhoud bepaal. Die toesighouer of bestuurder behoort nooit 'n onderhoud te voer wanneer sy gesindheid nie reg is nie of wanneer hy in 'n slegte luim verkeer nie. Tydsberekening speel dus 'n belangrike rol en moet altyd as 'n goue reël of voorwaarde vir 'n produktiewe en geslaagde onderhoud beskou word. Verder is eerlikheid en openhartigheid aan die kant van die onderhoudvoerder, essensieel. Pogings om die waarheid te omseil en die bespreking van delikate sake te vermy, is dikwels die rede waarom onderhoude van hierdie aard misluk.

'n Verdere riglyn, tot 'n gesonde merietebeoordelingstelsel is om die toesighouer/ bestuurder aanspreeklik te hou vir die akkuraatheid van die meriete-aanslag. Hierdie voorwaarde vir sukses, impliseer die noodsaaklikheid dat die topbestuur van 'n organisasie nie slegs belangstelling moet toon in die prestasiebeoordelingstelsel nie, maar dat hulle in werklikheid die hele stelsel moet beplan en bestuur. Indien die hoofbestuur geen of min belangstelling in die stelsel toon en verder in gebreke bly om bestuurders en toesighouers (dit wil sê die beoordelaars) tot verantwoording te roep, is die hele stelsel tot mislukking gedoem.

Aanspreeklikheid vir die akkuraatheid en suksesvolle implementering van 'n merietebeoordelingstelsel begin dus by die hoofbestuur van 'n onderneming. Op hul skouers rus die verantwoordelikheid om toe te sien dat hul ondergeskiktes die stelsel korrek en konsekwent toepas.

Om te verseker dat alle lynbestuurders en toesighouers merietebepaling as een van hul kerntake beskou, behoort dit in elkeen se posbeskrywing ingebou te word, en behoort hulle "gestraf" of "beloon" te word namate hulle hierdie plig en verantwoordelikheid uitvoer of ontduik.

Verder moet daarop gewys word dat die sukses, al dan nie, van 'n prestasiebeoordelingstelsel in 'n hoë mate bepaal word deur die "omgewing” waarbinne die stelsel fungeer, met 
spesifieke verwysing na belonings- en bevorderingspraktyke. Volle vertroue in, en vrywillige aanvaarding van 'n stelsel kan alleen geskied indien daar duidelike bewyse bestaan dat die topbestuur prestasiebeoordelingsresultate positief aanwend deur meriete direk en konsekwent aan salarisverhogings en bevorderings te koppel. Indien dit nie geskied nie is die reaksie van werknemers in die reël negatief en kan daar geen betekenisvolle en konstruktiewe resultate verwag word nie.

Verhogings en bevorderings moet te alle tye gekoppel word aan die ekonomiese waarde van 'n werknemer vir sy organisasie. Daar moet dus gedurig gewaak word dat verhogings en bevorderings nie weerhou word van talentvolle en bekwame werknemers wie se ekonomiese waarde vir die onderneming hoër is as hul huidige vergoeding en status nie. Verskonings vir die weerhouding van verdienstelikheidsverhogings soos "hy is alreeds bokant die gemiddelde van sy skaal" of "ander werkers sal beswaar maak", het (on)gelukkig geen plek meer in 'n positiewe prestasiebeoordelingstelsel nie.

Dan ook moet in gedagte gehou word dat strategiese tydsberekening by die toekenning van 'n salarisverhoging 'n belangrike rol kan speel by die motivering van 'n werker. ' $n$ Verhoging of bevordering direk en onmiddellik nadat 'n uitstaande prestasie gelewer is, het beslis groot motiveringswaarde; dikwels meer as 'n ewe groot of selfs groter beloning, later.

\section{DIE ONTWERP VAN 'N DOELTREFFENDE}

\section{PRESTASIEBEOORDELINGPROSEDURE}

Ten einde 'n effektiewe vorderingsoorsig (-onderhoud) te verseker word aan die hand gedoen dat die volgende sewe stappe gevolg word:

- Vroegtydige kennisgewing en voorbereiding.

In die eerste plek behoort die bestuurder of toesighouer wat as beoordelaar gaan optree seker te maak dat hy op die hoogte is met alle feite rakende die prestasies, vermoëns en vaardighede van die betrokke werknemer. Vir hierdie doel is 'n noukeurige hersiening van aantekeninge en rekords oor die werknemer se prestasies in die verlede nodig. Dit is verder belangrik om die werknemer vroegtydig in kennis te stel van die tyd en plek van samekoms sodat hy homself daarvoor kan voorberei.

- $\quad$ Skep van ' $n$ informele atmosfeer. 
'n Gespanne en formele atmosfeer belemmer in die reël goeie kommunikasie. Daar moet dus altyd gepoog word om 'n vriendelike en ontspanne atmosfeer te skep deur bv. vooraf aandag te gee aan aspekte soos 'n gerieflike tyd vir die werknemer, die rangskikking van sitplekke en die reëling van privaatheid.

- $\quad$ Oorsig van doelwitte.

Die werknemer is aan die woord en doen verslag oor die vordering wat hy gemaak het in die nastrewing van sy doelwitte, terwyl die toesighouer belangstellend luister, vrae vra en aantekeninge maak. Die werknemer word aangemoedig om openhartig te gesels terwyl die toesighouer die geleentheid kry om goeie prestasies raak te sien en aan te prys.

- Bespreking van ontwikkelingsbehoeftes.

Hierdie fase behels ' $n$ bespreking van die areas waarin die werknemer nie na wense vorder nie. Die trant van die gesprek is positief en die werknemer word aangespoor om met eie oplossings na vore te kom. Soos Sayles en Strauss (1977, p. 317) dit stel: "The superior then tries to encourage the subordinate to give his own picture of his progress, the problems he is meeting, and how these can be solved".

- Opsomming en konsensus oor wat bespreek is.

Die gesprek word afgerond met 'n opsomming deur die toesighouer met die doel om konsensus te bereik oor wat bespreek is en oor die besluite wat geneem is. Spesiale aandag word geskenk aan die verdere uitbouing van sterk punte en die regstelling van tekortkominge.

- Bevestiging en aanmoediging.

Uit 'n motiveringsoogpunt beskou is dit van groot belang om aan die ondergeskikte te bevestig dat hy 'n belangrike persoon in die organisasie is - een op wie se lojale medewerking en ondersteuning gereken word. 'n Gepaste woord van aanmoediging ten opsigte van toekomstige projekte en 'n herversekering dat hy op die hulp van sy hoofde kan staatmaak, behoort die werker verder aan te spoor om sy beste te lewer.

- Opvolging.

Ten slotte behoort die toesighouer deurlopende en volgehoue belangstelling in die werker en sy vordering te toon. Daarsonder kan dit maklik gebeur dat baie van die goeie werk wat gedoen is, ongedaan gemaak kan word. 


\section{SAMEVATTEND}

Positiewe prestasiebeoordeling wat in hierdie artikel bepleit word, verteenwoordig dus 'n geïntegreerde stelsel waarin elke werknemer in die onderneming:

- $\quad$ 'n Uitdagende stel doelwitte formuleer en nastreef;

- $\quad$ Die geleentheid kry om te kan presteer;

- $\quad$ Op hoogte is van hoe hy vorder;

- $\quad$ Raad en leiding van sy hoofde en gelykes ontvang wanneer nodig; en

- $\quad$ Beloon en bevorder word uitsluitlik volgens prestasies gelewer.

\section{OPSOMMING}

In hierdie artikel word ' $n$ meer positiewe benadering tot prestasiebeoordeling bepleit. Die onderwerp word onder die volgende hoofpunte bespreek: Leemtes in die tradisionele prestasiebeoordelingstelsels; Riglyne ten opsigte van ' $n$ meer doeltreffende merieteaanslag; en Die ontwerp van ' $n$ doeltreffende prestasiebeoordelingsprosedure. Die gevolgtrekking word gemaak dat die oplossing van beoordelingsprobleme geleë is in die nastrewing van " $n$ "stelsels-" of komprehensiewe benadering met besondere verwysing na menslike faktore, strukturele aspekte, dinamiese aspekte en omgewingsfaktore.

\section{VERWYSINGS}

Beer, M. \& Ruh, R. Employee growth through performance management. Harvard Business Review, July-August 1976, 59-66.

Flippo, E.B. Principles of Personnel Management. New York: McGraw-Hill, 1976.

Haynes, M.E. Developing an appraisal program. Personnel Journal, 1978, 57, 66-67, 104, 107.

Likert, R. Motivational approach to management development. Harvard Business Review, July-August 1959, 75.

McGregor, D. An uneasy look at performance appraisal. Harvard Business Review, 1957, 35(3), 90.

Orpen, C. The Principles of Personnel Psychology. Cape Town: Juta, 1979.

Sayles, L.R. \& Strauss, G. Managing Human Resources. Englewood Cliffs, N.J.: PrenticeHall, 1977.

Sikula, A.F. Personnel Administration and Human Resources Management. New York: John Wiley, 1976.

Strauss, G. \& Sayles, L.R. Personnel: The Human Problems of Management. London: Prentice-Hall, 1972. 